\title{
Thyroid Function in Patients with Acute Ischemic Stroke
}

\author{
Katarzyna Broczek ${ }^{1}$, Alicja Odwald-Wawreczko ${ }^{2}$ and Andrzej Opuchlik ${ }^{3}$ \\ ${ }^{1}$ Department of Geriatric Nursing, Medical University of Warsaw, Poland \\ ${ }^{2}$ Department of Gerontology and Geriatric Nursing, Medical University of Silesia, Poland \\ ${ }^{3}$ Department of Neurology, Medical University of Warsaw, Poland
}

Submission: April 10, 2021; Published: May 24, 2021

*Corresponding author: Katarzyna Broczek, Department of Geriatric Nursing, Medical University of Warsaw, 4 Oczki Str., 02-007 Warsaw, Poland

\begin{abstract}
Stroke is one of the major manifestations of cardiovascular diseases and a leading cause of long-term disability in older adults. Thyroid disfunction, as the most common endocrine disorder, may influence stroke risk and prognosis in multiple and complex ways. The aim of the study was to assess thyroid function in patients hospitalized with acute ischemic stroke. Thyroid hormone profile was evaluated in 50 consecutive patients hospitalized with ischemic stroke. A majority of patients had normal values of TSH, fT3 and fT4, but in 8 (16\%) patients, the serum level of thyroid hormones was out of the reference range indicating the need for further assessment. Stroke, as an acute and often severe disease, requires multidisciplinary care and thyroid function assessment may be helpful in the overall plan of treatment.
\end{abstract}

Keywords: Thyroid disorders; Ischemic stroke; Older adults; Hypothyroidism; Thyroid stimulating hormone; Hospitalization; Underdiagnosis

Abbreviations: fT3: Serum free triiodothyronine; fT4: Serum free thyroxine; T3: Triiodothyronine; T4: Thyroxine; TSH: Thyroid-Stimulating Hormone, Thyrotropin; AH: Arterial Hypertension; AF: Atrial Fibrillation; DM: Diabetes Mellltus

\section{Introduction}

The significance of cerebrovascular diseases as a public health problem is increasing worldwide due to the aging of the population. Stroke is an important cause of morbidity and mortality and one of the major factors contributing to loss of independence in older adults [1]. Thyroid disorders including subclinical hypo- and hyperthyroidism are common in the general population and their prevalence increases with age, although some studies suggest stability of thyroid function over time $[2,3]$. Complex pathways may be engaged in the relationship between stroke and thyroid function, reaching much further than the known correlations between hypothyroidism and atherosclerosis or hyperthyroidism and the risk of atrial fibrillation increasing the odds of a cardioembolic stroke [4-6]. Acute diseases, such as stroke, may cause euthyroid sick syndrome or nonthyroidal illness syndrome manifested by low serum triiodothyronine (T3) in individuals without previously diagnosed thyroid disease [7].

Moreover, studies suggests that thyroid status may influence recovery, prognosis, and outcomes of rehabilitation in stroke patients, but published data provide partially inconsistent results
[8-12]. Therefore, the complex interrelationships between the thyroid, the heart and the brain remain an area of interest with a potential for future prevention and treatment approaches. Screening for thyroid disorders is currently one of the most popular and widely accessible blood tests, although thyroid hormones alterations are often underdiagnosed and the laboratory results might be biased by a number of factors $[13,14]$. The aim of the present study was to assess thyroid function in patients hospitalized due to acute ischemic stroke.

\section{Material and Methods}

The study was conducted in the neurology department of a tertiary care university hospital in Warsaw, Poland. The study group comprised of 50 consecutive patients (24 females and 26 males) with acute ischemic stroke admitted to the stroke unit. The age range of patients was 35-91 years, but the majority $(80 \%)$ of patients were aged 60 years and over. Methods included: analysis of the medical documentation in terms of laboratory tests including thyroid hormones as well as coexisting diseases. Patients with preserved verbal communication were additionally 
questioned about history of thyroid diseases. Serum TSH was assessed in a routine diagnostic laboratory work-up in all patients, while serum fT3 and fT4 were available for 31 (64\%) of patients.

\section{Results and Discussion}

The patients were divided into two clinical categories based on their ability to communicate verbally with the research team: Group A: normal consciousness and preserved effective verbal communication ( $\mathrm{N}=35$, including $19 \mathrm{~F}, 16 \mathrm{M}$, mean age $66.9 \pm 17$ yr., age range 35-91 yr.), and Group B: poor or none verbal communication due to aphasia or altered mental status $(\mathrm{N}=15$, including 5 F, $10 \mathrm{M}$, mean age $77.5 \pm 11.9$ yr., age range $58-91 \mathrm{yr}$ ). The main results of the study are presented in Table 1, including serum TSH, fT3 and fT4 levels with indicated reference ranges. In total, any abnormality of thyroid hormones was found in $8(16 \%)$ of the patients with ischemic stroke and will be discussed below in detail.

Table 1: Characteristics of the patients with ischemic stroke including thyroid function and comorbidities.

\begin{tabular}{|c|c|c|c|c|}
\hline \multirow{2}{*}{ Characteristic } & Group A N=35 & Group B N=15 & Group $A+B N=50$ & Missing data \\
\hline & Number & Number & Number (\%) & Number (\%) \\
\hline Serum TSH in ref. range $0.27-4.2 \mathrm{mIU} / \mathrm{L}$ & 33 & 14 & $47(94)$ & - \\
\hline Serum TSH above $4.2 \mathrm{mIU} / \mathrm{L}$ & 2 & 0 & $2(4)$ & - \\
\hline Serum TSH below $0.27 \mathrm{mIU} / \mathrm{L}$ & 0 & 1 & $1(2)$ & - \\
\hline Serum fT3 in ref. range 3.1-6.8 pmol/L & 21 & 8 & $29(58)$ & \multirow{3}{*}{$19(38)$} \\
\hline Serum fT3 above $6.8 \mathrm{pmol} / \mathrm{L}$ & 0 & 0 & 0 & \\
\hline Serum fT3 below 3.1 pmol/L & 0 & 2 & $2(4)$ & \\
\hline Serum fT4 in ref. range $12-22 \mathrm{pmol} / \mathrm{L}$ & 19 & 8 & $27(54)$ & \multirow{3}{*}{$19(38)$} \\
\hline Serum fT 4 above $22 \mathrm{pmol} / \mathrm{L}$ & 1 & 2 & $3(6)$ & \\
\hline Serum fT 4 below $12 \mathrm{pmol} / \mathrm{L}$ & 1 & 0 & $1(2)$ & \\
\hline History of $\mathrm{AH}$ & 22 & 9 & $31(62)$ & - \\
\hline History of AF & 5 & 4 & $9(18)$ & - \\
\hline History of DM & 6 & 5 & $11(22)$ & - \\
\hline History of dyslipidemia & 7 & 3 & $10(20)$ & - \\
\hline Thyroid disease reported by the patient & 8 & - & - & - \\
\hline
\end{tabular}

Serum TSH was normal in the majority $(47 ; 94 \%)$ of ischemic stroke patients. In the group A consisting of patients who could answer the question about previous thyroid disease, 8 patients confirmed history of thyroid disorders. Two patients in the group A had serum TSH levels above the limit, indicating possible subclinical hypothyroidism: $7.19 \mathrm{mIU} / \mathrm{mL}$ in an 81-year-old female with known thyroid disease, and $4.46 \mathrm{mIU} / \mathrm{mL}$ in a 58year-old female without previous thyroid disorder. It is, however, worth noting that serum TSH in these patients did not exceed the value of $10 \mathrm{mIU} / \mathrm{mL}$, accepted as the threshold of significant abnormality warranting treatment. Additionally, in the group A, two patients had serum fT4 levels slightly above the upper limit with normal values of TSH and fT3, none of them reported previous thyroid disorders.

Among patients in the group B who were not capable of responding to the question about previous thyroid disease, one case of hyperthyroidism was found in an 83-year-old male with serum TSH $0.1 \mathrm{mIU} / \mathrm{mL}$, fT4 of $26 \mathrm{pmol} / \mathrm{L}$ and normal fT3. Additionally, in the group B, one patient, an 88-year-old male had fT4 level just above the upper limit, with normal TSH and fT3 values. In two other patients, low fT3 was found with values just below the lower reference limit, and normal values of TSH and
fT4. It occurred in a 66-year-old male and a 91-year-old female. It these two cases, euthyroid sick syndrome might be suspected as a reaction to acute stroke.

Only one in eight patients reporting previous thyroid disease had abnormal value of TSH. It is, however, worth mentioning that brain research studies indicate that even treated hypothyroidism is a risk factor for significant cerebrovascular pathology [15]. Moreover, low T3 has been shown to correlate with a long-term post-stroke cognitive impairment [16]. In the present study, over half of the patients had the history of hypertension and one in five was previously diagnosed with diabetes, atrial fibrillation and/or dyslipidemia, commonly known risk factors for ischemic stroke (Table 1). A new consensus on cardiovascular care for stroke patients of the European Society of Cardiology underlines the role of interdisciplinary approach [17]. It is, therefore, deeply disappointing that this document does not mention the importance of thyroid function assessment.

In patients with stroke, various additional factors might influence thyroid function including iodinated contrast brain imaging, acute therapy of cardiovascular complications (e.g., amiodarone) or use of low molecular weight heparin preparation potentially causing abnormal thyroid tests [18-20]. Pre-admission 
medication lists and hospital treatment were not analyzed in the current study. The strengths of the present study include the assessment of consecutive patients with ischemic stroke, thus avoiding selection bias as well as availability of serum TSH level tested as a routine procedure upon admission to a stroke unit. Limitations of our study include relatively small number of patients, single assessment of thyroid hormones, missing data for fT3 and fT 4 in 38\% of patients, and lack of analysis of medications.

\section{Conclusion}

The majority of patients hospitalized with the diagnosis of acute ischemic stroke have normal thyroid function, but approximately one in six patients requires further assessment. Thyroid function and patients' awareness of thyroid health should be assessed in stroke patients. Follow-up of thyroid function should be carefully planned in selected patients, as diagnostic procedures and hospital treatment may increase the risk of thyroid disorders.

\section{References}

1. GBD 2016 Stroke Collaborators (2019) Global, regional and national burden of stroke, 1990-2016: a systematic analysis from the Global Burden of Disease Study 2016. Lancet Neurol 18(5): 439-458.

2. Barbesino G (2018) Thyroid function changes in the elderly and their relationship to cardiovascular health: A mini-review. Gerontology 65(1): 1-8.

3. Roberts S, McCahon D, Johnson O, Haque MS, Parle J, et al. (2018) Stability of thyroid function in older adults: The Birmingham Elderly Thyroid Study. Brit J Gen Pract 68(675): e718-e726.

4. Liu J, Cui X, Wang D, Wu S, Xiong Y, et.al. (2017) Relationship of thyroid function with intracranial arterial stenosis and atheromatous plaques in ischemic stroke patients with euthyroidism. Oncotarget 8(28): 46532-46539.

5. Larsson S, Allara E, Mason MA, Michaelsson K, Burges S (2019) Thyroid function and dysfunction in relations to 16 cardiovascular diseases: A Mendelian randomization study. Circ Gen Prec Med 12(3): e002608.

6. Wang L, Zhang Y (2020) Role of hyperhomocysteine, thyroid dysfunction and their interaction in ischemic stroke patients with nonvalvular atrial fibrillation. Sci Rep 10(12419): 1-5.

7. Huang GQ, Zeng YY, Cheng QQ Cheng HR, Cheng HR, et.al. (2019) Low triiodothyronine syndrome is associated with hemoragic transformation in patients with acute ischemic stroke. Aging 11(16): 6385-6397.
8. Talhada D, Santos CRA, Goncalves I, Ruscher K (2019) Thyroid hormones on the brain and their impact in recovery mechanisms after stroke. Front Neurol 10(1103): 1-16.

9. Jiang X, Xing H, Wu J, Du R, Liu H, et.al. (2017) Prognostic value of thyroid hormones in acute ischemic stroke - a meta-analysis. Sci Rep $7(1): 16256$.

10. Li LQ, Xu XJ, Li WY, Hu XY, Lv W (2019) The prognostic value of total T3 after acute cerebral infarction is age-dependent: A retrospective study on 768 patients. BMC Neurology 19(54): 1-7.

11. Boltzmann M, Schmidt SB, Rollnik JD (2017) Impact of thyroid hormone levels on functional outcome in neurological and neurosurgical early rehabilitation patients. BioMed Research International 47(19279): 1-7.

12. Zhang S, Zhao X, Xu S, Yuan J, Si Z, et al.(2019) Low free triiodothyronineis predicts worsen neurological outcome of patients with acute ischemic stroke: A retrospective study with bioinformatics analysis. BMC Neurol 19(272): 1-14.

13. Mendes D, Alves C, Silverio N, Batel Marques F (2019) Prevalence of undiagnosed hypothyroidism in Europe: A systematic review and meta-analysis. Eur Thyroid J 8(3): 130-143.

14. Kortenkamp A, Axelstad M, Baig AH, Bergman A, Bornehag CG (2020) Removing critical gaps in chemical test methods by developing new assays for the identification of thyroid hormone system-disrupting chemicals - The Athena project. Int J Mol Sci 21(3123): 1-13.

15. Brenowitz WD, Han F, Kukull WA, Nelson PT (2018) Treated hypothyroidism is associated with cerebrovascular disease but not Alzheimer's disease pathology in older adults. Neurobiol Aging 62: 6471.

16. Mao L, Chen XH, Zhuang JH, Li P, Xu YX, et al. (2020) Relationship between $\beta$-amyloid protein, thyroid hormone levels and the risk of cognitive impairment after ischemic stroke. World J Clin Cases 8(1): 76-87.

17. Doehner W, Mazighi M, Hofmann BM, Lautsch D, Hindricks G, et al. (2020) Cardiovascular care of patients with stroke and high risk of stroke: The need for interdisciplinary action: A consensus report from the European Society of Cardiology Cardiovascular Round Table. Eur J Prev Cardiol 27(7): 682-692.

18. Lee SY, Rhee CN, Leung AM, Braverman LE, Brent GA, et al. (2015) A review: Radiographic iodinated contrast media-induced thyroid dysfuntion. J Clin Endocrinol Metab 100(2): 376-383.

19. Rusandu A, Sjovold BH, Hofstad E, Johansen Reidunsdatter R (2020) Iodinated contrast media and their effect on thyroid function - Routines and practices among diagnostic imaging departments in Norway. J Med Radiat Sci 67(2): 111-118.

20. Burch HB (2019) Drug effect on the thyroid. N Eng J Med 381(8): 749761. 
(C) (ن) This work is licensed under Creative Commons Attribution 4.0 Licens DOI: $10.19080 / J E T R .2021 .06 .555680$
- Quality Editorial service

- Swift Peer Review

- Reprints availability

- E-prints Service

- Manuscript Podcast for convenient understanding

- Global attainment for your research

- Manuscript accessibility in different formats

(Pdf, E-pub, Full Text, Audio)

- Unceasing customer service

Track the below URL for one-step submission https://juniperpublishers.com/online-submission.php 